\title{
Association of nicotinic acetylcholine receptors with central respiratory control in isolated brainstem-spinal cord preparation of neonatal rats
}

\author{
EIKI HATORI ${ }^{1}$, SHIGEKI SAKURABA ${ }^{1}$, MASANORI KASHIWAGI $^{1,2}$, JUNYA $^{2}$ \\ KURIBAYASHI $^{1}$, MIKI TSUJITA ${ }^{1}$, YUKI HOSOKAWA ${ }^{1}$, JUNZO TAKEDA ${ }^{1}$ and \\ SHUN-ICHI KUWANA ${ }^{3}$ \\ ${ }^{1}$ Department of Anesthesiology, School of Medicine, Keio University, Tokyo, Japan . \\ 2 Department of Anesthesiology, Kitasato Institute Hospital, The Kitasato Institute, Tokyo, Japan. \\ ${ }^{3}$ Department of Physiology, School of Medicine, Teikyo University, Tokyo, Japan.
}

\begin{abstract}
Nicotine exposure is a risk factor in several breathing disorders Nicotinic acetylcholine receptors (nAChRs) exist in the ventrolateral medulla, an important site for respiratory control. We examined the effects of nicotinic acetylcholine neurotransmission on central respiratory control by addition of a nAChR agonist or one of various antagonists into superfusion medium in the isolated brainstem-spinal cord from neonatal rats. Ventral C4 neuronal activity was monitored as central respiratory output, and activities of respiratory neurons in the ventrolateral medulla were recorded in whole-cell configuration. RJR-2403 (0.1-10 $\mu \mathrm{M}), \alpha 4 \beta 2 \mathrm{nAChR}$ agonist induced dose-dependent increases in respiratory frequency. Non-selective nAChR antagonist mecamylamine $(0.1-100 \mu \mathrm{M}), \alpha 4 \beta 2$ antagonist dihydro- $\beta$-erythroidine $(0.1-100 \mu \mathrm{M}), \alpha 7$ antagonist methyllycaconitine $(0.1-100 \mu \mathrm{M})$, and $\alpha$-bungarotoxin $(0.01-10 \mu \mathrm{M})$ all induced dose-dependent reductions in $\mathrm{C} 4$ respiratory rate. We next examined effects of $20 \mu \mathrm{M}$ dihydro- $\beta$-erythroidine and $20 \mu \mathrm{M}$ methyllycaconitine on respiratory neurons. Dihydro- $\beta$-erythroidine induces hyperpolarization and decreases intraburst firing frequency of inspiratory and preinspiratory neurons. In contrast, methyllycaconitine has no effect on the membrane potential of inspiratory neurons, but does decrease their intraburst firing frequency while inducing hyperpolarization and decreasing intraburst firing frequency in preinspiratory neurons. These findings indicate that $\alpha 4 \beta 2 \mathrm{nAChR}$ is involved in both inspiratory and preinspiratory neurons, whereas $\alpha 7 \mathrm{nAChR}$ functions only in preinspiratory neurons to modulate $\mathrm{C} 4$ respiratory rate.
\end{abstract}

Key terms: brainstem-spinal cord, neonatal rat, inspiratory neuron, preinspiratory neuron, nicotinic acetylcholine receptor.

\section{INTRODUCTION}

In central respiratory control, chemosensitive neurons in the rostral ventrolateral medulla (RVLM) are thought to provide tonic drive to the neuronal network (Eugenin and Nicholls, 1997; Richerson, 1998; Eugenin et al., 2001), which mainly comprises inspiratory (Insp) neurons and preinspiratory (Pre-I) neurons involved in the generation of respiratory rhythm (Onimaru and Homma, 1987, 2003; Onimaru et al., 1988, 1989, 1997).
Acetylcholine ( $\mathrm{ACh}$ ) is an excitatory neurotransmitter that functions in central respiratory control (Murakoshi et al., 1985; Monteau et al., 1990; Burton et al., 1995; Shao and Feldman, 2000, 2001, 2002, 2005), including central chemosensitivity (Monteau et al., 1990; Burton et al., 1997; Eugenin and Nicholls, 1997; Eugenin et al., 2001; Okada et al., 2001; Sakuraba et al., 2005). Both muscarinic and nicotinic ACh receptors have been shown to participate in the cholinergic mechanisms that help regulate respiratory rhythm.

Corresponding author: Shun-ichi Kuwana, Ph.D, Department of Physiology, School of Medicine, Teikyo University, 2-11-1 Kaga, Itabashi-ku, Tokyo 173-8605, Japan, Tel: (81-3) 3964-1211, ext. 2141, Fax: (81-3) 5248-1415, E-mail: kuwanas@med.teikyo-u.ac.jp 
Maternal cigarette smoking is indicated as a major dose-dependent risk factor in sudden infant death syndrome (Blair et al., 1996). Prenatal nicotine exposure also has been linked to a high incidence of apnea and altered breathing pattern in neonatal rodent (Robinson et al., 2002; Huang et al., 2004), although the contribution of nicotinic $\mathrm{ACh}$ receptors (nAChRs) to central respiratory activity remains imperfectly understood.

In the RVLM, which includes central respiratory control, nAChRs comprising $\alpha 4 \beta 2$ and $\alpha 7$ are expressed (Wada et al., 1989; Dominguez del Toro et al., 1994). In medullary slice preparations from neonatal rats that generate respiratory rhythm (Smith et al., 1991), nicotine induces increases in respiratory frequency and activations of inspiratory neuron (Shao and Feldman, 2001). These increases are antagonized by $\alpha 4 \beta 2$ nicotinic antagonist dihydro- $\beta$-erythroidine (DH- $\beta$-E), while $\alpha 7$ antagonist $\alpha$-bungarotoxin ( $\alpha$-BgTx) and methyllycaconitine (MLA) have no effects on nicotine-induced respiratory activation (Shao and Feldman, 2002). These findings suggest that the predominant subtype of $\mathrm{nAChR}$ involved in central respiratory control is the $\alpha 4 \beta 2$ combination, not the homomeric $\alpha 7$ subunit. However, these studies were conducted in medullary slice preparations, in which the Pre-I neuron network is absent. This may be significant as Pre-I neurons have been shown to act as a source of respiratory rhythm generation and to trigger periodic activity in inspiratory neuron network in brainstemspinal cord preparations of neonatal rats (Onimaru et al., 1988, 1989, 1997; Onimaru and Homma, 2003).

Recent studies have indicated that both Pre-I neurons and Insp neurons are essential for respiratory rhythmogensis in brainstemspinal cord preparations (Takeda et al., 2001; Mellen et al., 2003; Sakuraba et al., 2003). In a previous study, we found that neuromuscular blocking agents (NMBAs), which function as muscular nAChR antagonists, exert their inhibitory effects on Pre-I neurons (Sakuraba et al., 2003). This finding led us to hypothesize that some subtypes of nAChRs might participate in the modulation of respiratory activities, such as rhythm generation, in the central respiratory network, comprising both Pre-I and Insp neurons. However, in brainstemspinal cord preparations of neonatal rats in which the complete central respiratory network remains intact, it has been reported that the application of individual nAChR antagonists, such as the ganglion blocker mecamylamine (Meca) or the NMBA gallamine, does not affect $\mathrm{C} 4$ respiratory rate (Monteau et al., 1990).

In the present study, we reevaluate the effects of the sole application of nAChR antagonist and agonist on $\mathrm{C} 4$ respiratory rate in an attempt to clarify which subtypes of nAChRs participate in the central respiratory network comprising both Pre-I and Insp neurons.

\section{MATERIALS AND METHODS}

All procedures were conducted in accordance with the guidelines set forth by the scientific committee of Teikyo University. Data were obtained from 147 neonatal rats (0-4 days old, Wistar rats).

\section{Isolated brainstem-spinal cord preparation}

The isolated brainstem-spinal cord has been described in detail elsewhere (Kuwana et al., 1998; Sakuraba et al., 2003). In brief, the rats were deeply anesthetized with diethyl ether, and the brainstem and cervical spinal cord were isolated in a chamber filled with oxygenated artificial cerebrospinal fluid (ACSF). The cerebellum and pons were ablated. The preparation was transferred to a 2-ml recording chamber and fixed, ventral side up, to a silicon rubber base with miniature pins. The preparation was superfused at $26^{\circ} \mathrm{C}$ in control ACSF equilibrated with a control gas mixture $(5 \%$ $\mathrm{CO}_{2}$ in $\left.\mathrm{O}_{2} ; \mathrm{pH}=7.4\right)$. The activity of $\mathrm{C} 4$ ventral roots was recorded using a glass suction electrode, amplified by a conventional AC amplifier (AVH 11, Nihon Kohden, Tokyo, Japan), and integrated (time constant $100 \mathrm{msec}$ ). Signals were 
recorded on a thermal array recorder and stored on digital tape for subsequent analysis. The control ACSF was replaced by various ACSF solutions, as determined by the protocols described below.

\section{Neuronal recording}

The intracellular activity of Insp and Pre-I neurons in the superficial $(<400 \mu \mathrm{m})$ RVLM was recorded using a perforated patch clamp (Kuwana et al., 1998; Sakuraba et al., 2003). Neurons were identified and classified on the basis of their firing patterns and the temporal correlation of their activity to the respiratory cycle of the $\mathrm{C} 4$ ventral root activity (Onimaru et al., 1997; Sakuraba et al., 2003). Insp neurons discharge action potentials during the inspiratory phase $(\mathrm{C} 4$ burst activity phase). Pre-I neurons are characterized by preinspiratory and postinspiratory action potential discharges. A glass pipette (GC100-TF-10, Clark, Reading, UK) was pulled using a horizontal puller (PA-91, Narishige, Tokyo, Japan) to a tip size of approximately $2 \mu \mathrm{m}$. Electrode resistance ranged from 12 to $16 \mathrm{M} \Omega$ when the pipette was filled with a solution containing (in $\mathrm{mM}$ ) $140 \mathrm{~K}$-gluconate, $3 \mathrm{KCl}$, 10 EGTA, 10 HEPES, $1 \mathrm{CaCl}_{2}, 1 \mathrm{MgCl}_{2}$, and nystatin $(100 \mu \mathrm{g} / \mathrm{ml})$. $\mathrm{pH}$ was maintained at 7.2-7.3 using $\mathrm{KOH}$. The micropipette was inserted into the RVLM using a manual hydraulic micromanipulator. Membrane potentials were recorded using a single-electrode voltage clamp amplifier (CEZ 3100, Nihon Kohden, Tokyo, Japan). Neurons were located by applying positive pressure $\left(10-20 \mathrm{~cm} \mathrm{H}_{2} \mathrm{O}\right)$ inside the pipette. After a gigaohm seal was obtained, the recorded membrane potential gradually became negative and stabilized in about 10 min. The membrane potential $\left(E_{m}\right)$ was presented without correcting the liquid junction potential. The resulting perforated patch recording remained stable for more than $60 \mathrm{~min}$.

\section{Protocols}

After the preparation was superfused with control ACSF for at least $30 \mathrm{~min}$ and the C4 activity reached a steady state, the control
ACSF was replaced by several ACSF solutions containing nicotinic antagonist or agonist in accordance with the protocol. Mecamylamine hydrochloride (Meca, nonselective $\mathrm{nAChR}$ antagonist), dihydro- $\beta$ erythroidine hydrobromide (DH- $\beta$-E, $\alpha 4 \beta 2$ nAChR antagonist), methyllycaconitine citrate (MLA, $\alpha 7 \mathrm{nAChR}$ antagonist), $\alpha$ bungarotoxin $(\alpha-\mathrm{BgTx}, \quad \alpha 7 \mathrm{nAChR}$ antagonist), and RJR-2403 hemigalactarate (RJR, $\quad \alpha 4 \beta 2$ nAChR agonist) were purchased from Sigma-Aldrich corporation (St. Louis, Missouri, USA). Experiments were conducted under the protocols described below.

Protocol-1: Neuronal nicotinic acetylcholine receptor subunit and $C 4$ respiratory rate

We analyzed the effects of a nAChR agonist and several antagonists on $\mathrm{C} 4$ respiratory rate. After making a baseline recording, the control ACSF was replaced by ACSF containing Meca, DH- $\beta$-E, MLA $(0.1,1,10,100 \mu \mathrm{M}), \alpha-\operatorname{BgTx}(0.01,0.1$, $1.0 \mu \mathrm{M})$ or RJR $(0.1,1.0,10 \mu \mathrm{M})$ for $10 \mathrm{~min}$, followed by a washout period using the control ACSF for $10 \mathrm{~min}$.

\section{Protocol-2: Neuronal nicotinic acetylcholine receptor subunit and respiratory neurons}

We analyzed the effects of DH- $\beta$-E and MLA on Insp and Pre-I neurons in the RVLM. After the control recording, control ACSF was replaced to ACSF containing DH- $\beta$-E or MLA $(20 \mu \mathrm{M})$ for $10 \mathrm{~min}$, followed by a $10 \mathrm{~min}$ washout period in which control ACSF was reintroduced. We examined intraburst firing frequency, drive potential amplitude, and drive potential duration to assess changes in the drive respiratory potential of Insp and Pre-I neurons. Intraburst firing frequency was calculated as the number of spikes per firing period. Drive potential amplitude was defined as the voltage difference between resting $E_{m}$ in the silent phase of the respiratory cycle and the peak plateau potential (without spikes) during depolarization. Drive potential duration was defined as the duration of the respiratory 
neuron depolarization cycle. And depolarizing cycle rate was defined as the number of depolarization per minute.

\section{Statistical analyses}

All data before and during the application of drugs were analyzed using the paired-t test. $P<0.05$ was considered significant. Data are expressed as mean \pm S.E.M.

\section{RESULTS}

Neuronal nicotinic acetylcholine receptor subunit and $C 4$ respiratory rate

Meca $(0.1,1,10,100 \mu \mathrm{M})$, DH- $\beta$-E $(0.1,1$, 10, 100uM) (Fig. 1A), MLA $(0.1,1,10$, $100 \mu \mathrm{M})$ (Fig. 1B), and $\alpha-\operatorname{BgTx}(0.01,0.1$, $1.0 \mu \mathrm{M})$ all significantly reduced $\mathrm{C} 4$ respiratory rate (Table $1 ; \mathrm{n}=102$ ). In contrast, RJR significantly increased C4 respiratory rate (Fig. 1C; Table $1 ; \mathrm{n}=21$ ). These nAChR antagonists and agonists induced no changes in integrated $\mathrm{C} 4$ amplitude (data not shown).

Neuronal nicotinic acetylcholine receptor subunit and respiratory neurons in RVLM

We analyzed the effects of DH- $\beta$-E and MLA on 24 respiratory neurons in RVLM. We classified these neurons into two groups - Insp and Pre-I neurons - based on their firing patterns during perfusion with control ACSF. The application of DH- $\beta$-E $20 \mu \mathrm{M}(\mathrm{n}$ $=12)$ and MLA $20 \mu \mathrm{M}(\mathrm{n}=12)$ decreased $\mathrm{C} 4$ respiratory rate from $5.3 \pm 0.6$ to $3.4 \pm$ $0.5 \mathrm{~min}^{-1}(\mathrm{P}<0.01)$ and from $4.8 \pm 0.4$ to $2.8 \pm 0.2 \mathrm{~min}^{-1}(\mathrm{P}<0.01)$, respectively.

Effects of DH- $\beta$-E and MLA on Insp neurons

DH- $\beta$-E and MLA decreased C4 respiratory rate and depolarizing cycle rate in Insp neurons (Fig. 2; Table 2). DH- $\beta$-E induced hyperpolarization of $E_{m}$ and decreased intraburst firing frequency, drive potential duration, and drive potential amplitude during $\mathrm{DH}-\beta$-E-induced respiratory depression (Fig. 2A; Table 2). MLA significantly decreased intraburst firing frequency of Insp neurons, but did not induce any changes in $\mathrm{E}_{\mathrm{m}}$, drive potential duration, or amplitude (Fig. 2B; Table 2).

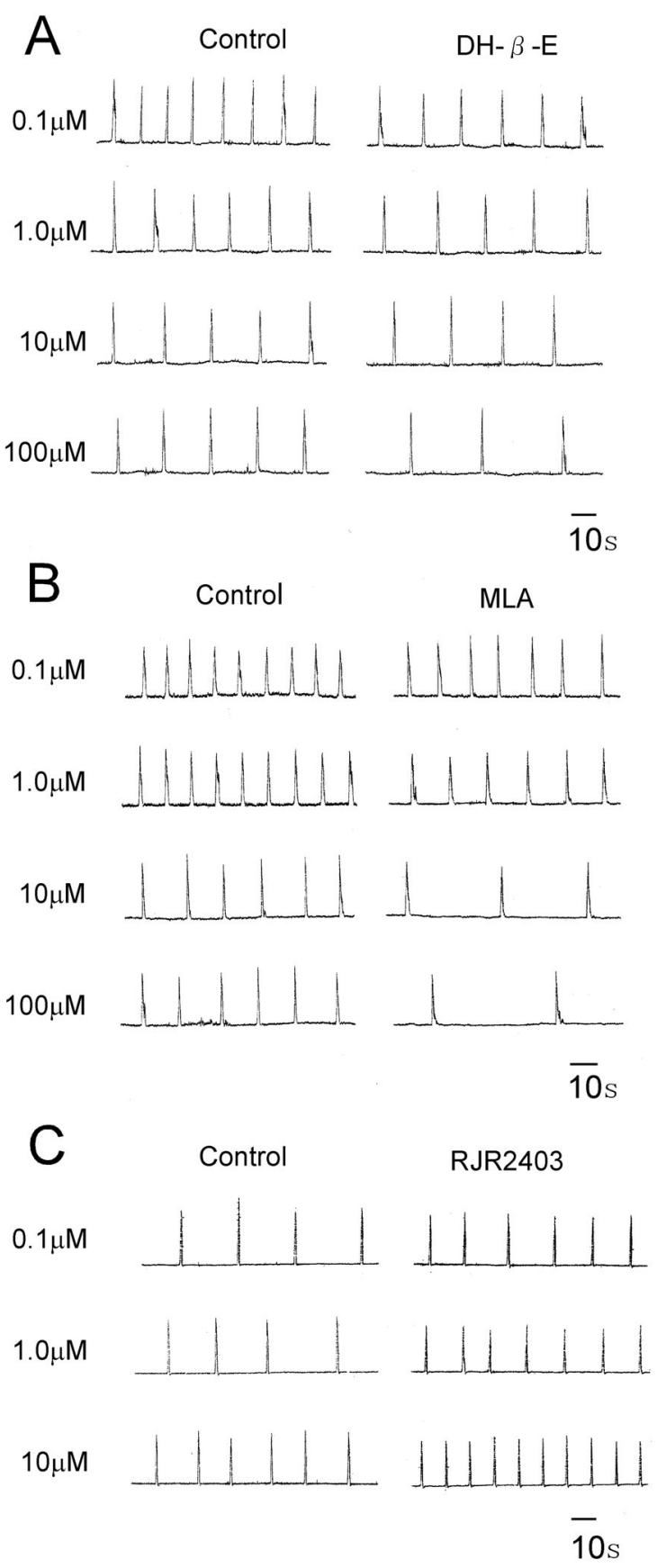

Figure 1: Representative recording of integrated $\mathrm{C} 4$ activity before and during the application of (A) DH- $\beta$-E $(0.1,1,10,100 \mu \mathrm{M})$, (B) MLA $(0.1,1,10,100 \mu \mathrm{M})$ and (C) RJR (0.1, $1,10 \mu \mathrm{M})$. 


\section{TABLE 1}

Effects of $\mathrm{nAChR}$ antagonists and agonists on $\mathrm{C} 4$ respiratory rate

\begin{tabular}{lrllll}
\hline Drug & Concentration $(\mu \mathrm{M})$ & $\mathrm{n}$ & \multicolumn{2}{c}{ C4 respiratory rate $\left(\mathrm{min}^{-1}\right)$} \\
& & & Control & Drug $(\%$ of control $)$ & Washout \\
\hline Meca & 0.1 & 7 & $5.5 \pm 0.3$ & $4.5 \pm 0.3 *(81.4 \pm 3.0)$ & $5.3 \pm 0.3$ \\
& 1 & 7 & $5.4 \pm 0.3$ & $4.0 \pm 0.3 * *(73.0 \pm 2.7)$ & $4.9 \pm 0.3$ \\
& 10 & 7 & $5.3 \pm 0.3$ & $3.5 \pm 0.5 * * *(65.0 \pm 4.7)$ & $4.8 \pm 0.3$ \\
DH- $\beta$-E & 100 & 7 & $5.6 \pm 0.4$ & $3.5 \pm 0.4 * * *(61.4 \pm 3.2)$ & $4.3 \pm 0.6$ \\
& 0.1 & 7 & $6.8 \pm 0.7$ & $5.6 \pm 0.7 * *(82.3 \pm 3.2)$ & $6.4 \pm 0.7$ \\
& 1 & 7 & $6.7 \pm 0.6$ & $5.1 \pm 0.7 * * *(74.5 \pm 4.3)$ & $6.2 \pm 0.7$ \\
& 10 & 7 & $6.7 \pm 0.8$ & $4.4 \pm 0.8 * *(62.0 \pm 6.6)$ & $6.1 \pm 0.8$ \\
MLA & 100 & 7 & $7.3 \pm 0.7$ & $4.0 \pm 0.8 * * *(51.6 \pm 6.4)$ & $4.9 \pm 0.4$ \\
& 0.1 & 7 & $6.1 \pm 0.7$ & $4.8 \pm 0.7 * *(77.2 \pm 2.8)$ & $5.6 \pm 0.7$ \\
& 1 & 7 & $6.2 \pm 0.7$ & $4.4 \pm 0.8 * * *(66.9 \pm 5.3)$ & $5.8 \pm 0.6$ \\
$\alpha-B g T x$ & 10 & 7 & $6.3 \pm 0.8$ & $3.6 \pm 0.8 * * *(52.7 \pm 5.8)$ & $5.5 \pm 0.8$ \\
& 100 & 7 & $6.1 \pm 0.8$ & $3.0 \pm 0.8 * * *(44.1 \pm 6.5)$ & $5.5 \pm 0.8$ \\
& 0.01 & 6 & $6.1 \pm 0.4$ & $5.2 \pm 0.5 * *(84.4 \pm 3.0)$ & $5.9 \pm 0.4$ \\
RJR & 0.1 & 6 & $6.4 \pm 0.4$ & $4.8 \pm 0.3 * * *(74.8 \pm 2.2)$ & $6.1 \pm 0.4$ \\
& 1 & 6 & $6.9 \pm 0.6$ & $4.8 \pm 0.5 * * *(69.1 \pm 3.1)$ & $5.9 \pm 0.5$ \\
& 0.1 & 7 & $4.8 \pm 0.8$ & $5.3 \pm 0.6 * * *(110.3 \pm 1.9)$ & $4.9 \pm 0.9$ \\
& 1 & 7 & $5.0 \pm 0.6$ & $6.2 \pm 0.7 * *(122.3 \pm 3.5)$ & $5.3 \pm 0.6$ \\
& 10 & 7 & $5.2 \pm 0.4$ & $10.6 \pm 1.3 * *(202.8 \pm 12.7)$ & $6.1 \pm 0.3$ \\
\hline
\end{tabular}

Meca: mecamylamine; DH- $\beta$-E: dihydro- $\beta$-erythroidine; MLA: methyllycaconitine; a-BgTx: a-bungarotoxin; RJR: RJR-2403

$* P<0.05$

$* * P<0.01$

$* * * P<0.001$
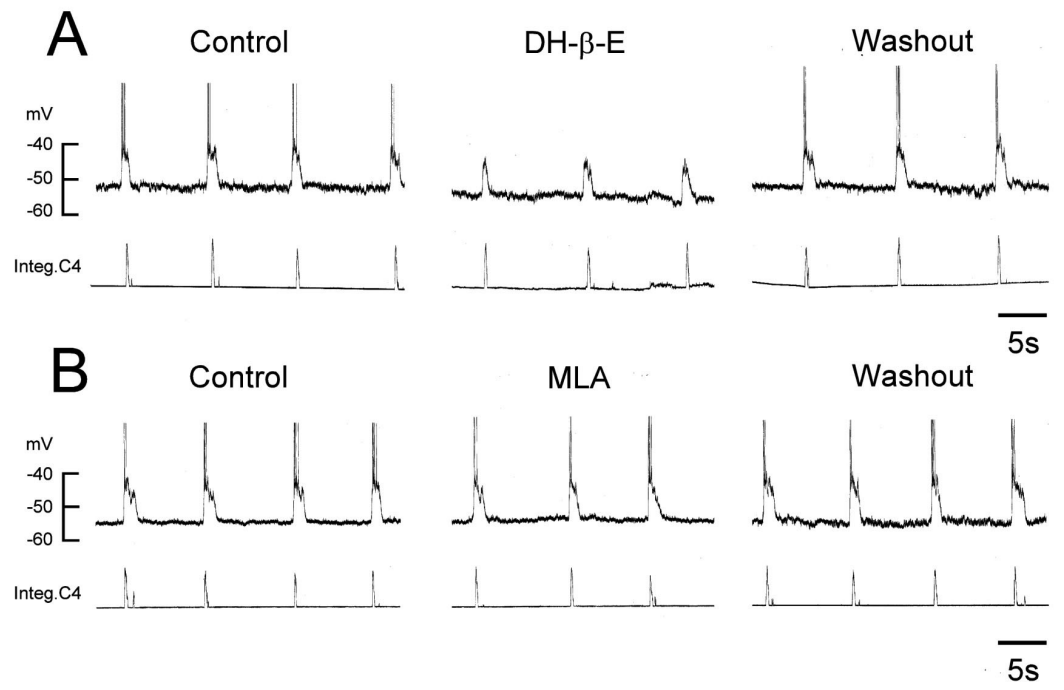

Figure 2: Effects of DH- $\beta$-E (A) and MLA (B) on the activity of inspiratory neurons. Top traces show the membrane potential of inspiratory neurons before (Control), during (DH- $\beta$-E $20 \mu \mathrm{M}$ or MLA $20 \mu \mathrm{M}$ ), and after the application of DH- $\beta$-E and MLA. Bottom traces show integrated C4 (Integ.C4) activity (Washout). 
TABLE 2

Effects of DH- $\beta$-E and MLA on inspiratory neuron and $\mathrm{C} 4$ respiratory rate

\begin{tabular}{|c|c|c|c|c|c|c|}
\hline & \multicolumn{3}{|c|}{ DH- $\beta-E 20 \mu M(n=6)$} & \multicolumn{3}{|c|}{ MLA $20 \mu M(n=6)$} \\
\hline & Control & DH- $\beta-\mathrm{E}$ & Washout & Control & MLA & Washout \\
\hline $\mathrm{C} 4$ respiratory rate $\left(\mathrm{min}^{-1}\right)$ & $5.8 \pm 0.8$ & $3.6 \pm 0.6 * * *$ & $5.2 \pm 0.7$ & $5.1 \pm 0.5$ & $3.1 \pm 0.5 * * *$ & $4.9 \pm 0.5$ \\
\hline Depolarizing cycle rate $\left(\mathrm{min}^{-1}\right)$ & $5.8 \pm 0.8$ & $3.6 \pm 0.6^{* * *}$ & $5.2 \pm 0.7$ & $5.1 \pm 0.5$ & $3.1 \pm 0.5 * * *$ & $4.9 \pm 0.5$ \\
\hline Intraburst firing frequency $(\mathrm{Hz})$ & $16.1 \pm 3.6$ & $10.4 \pm 2.7 * *$ & $15.0 \pm 3.3$ & $11.4 \pm 2.2$ & $10.9 \pm 2.2 *$ & $11.2 \pm 2.3$ \\
\hline $\mathrm{E}_{\mathrm{m}}(\mathrm{mV})$ & $-53.9 \pm 0.6$ & $-59.1 \pm 1.0^{* * *}$ & $-55.1 \pm 1.0$ & $-55.5 \pm 0.7$ & $-55.6 \pm 0.7$ & $-55.7 \pm 0.8$ \\
\hline Drive potential duration (s) & $1.9 \pm 0.2$ & $1.3 \pm 0.1 * * *$ & $1.8 \pm 0.2$ & $1.6 \pm 0.1$ & $1.6 \pm 0.1$ & $1.6 \pm 0.1$ \\
\hline Drive potential amplitude $(\mathrm{mV})$ & $9.6 \pm 1.3$ & $7.4 \pm 0.7 *$ & $9.0 \pm 1.2$ & $9.4 \pm 1.3$ & $9.2 \pm 1.2$ & $9.2 \pm 1.2$ \\
\hline
\end{tabular}

DH- $\beta$-E: dihydro- $\beta$-erythroidine; MLA: methyllycaconitine; $\mathrm{E}_{\mathrm{m}}$ : membrane potential

$* P<0.05$

$* * P<0.01$

$* * * P<0.001$

Effects of DH- $\beta-E$ and MLA on Pre-I neurons

Both DH- $\beta$-E and MLA decreased C4 respiratory rate and depolarizing cycle rate and induced significant hyperpolarization of $E_{m}$ and reduction of intraburst firing frequency (Fig. 3; Table 3).

\section{DISCUSSION}

The present study has shown that $\alpha 4 \beta 2$ $\mathrm{nAChR}$ antagonist DH- $\beta-\mathrm{E}$ and $\alpha 7 \mathrm{nAChR}$ antagonists MLA and $\alpha-B g$ Tx decrease C4 respiratory rate in a dose-dependent fashion, while the $\alpha 4 \beta 2$ nAChR agonist RJR induces dose-dependent increases in $\mathrm{C} 4$ respiratory rate. These results indicate that both $\alpha 4 \beta 2$ and $\alpha 7$ nAChR subtypes participate in the regulation of respiratory activity in preparations of neonatal rat brainstem-spinal cord.

In addition, we have shown that the $\alpha 4 \beta 2$ nAChR antagonist DH- $\beta$-E induces hyperpolarization of $\mathrm{E}_{\mathrm{m}}$ and decreases in intraburst firing frequency in both Insp and Pre-I neurons. The $\alpha 7 \mathrm{nAChR}$ antagonist MLA, however, has distinct effects on each of the major respiratory neuron populations: in Insp neurons, MLA does not affect $\mathrm{E}_{\mathrm{m}}$ polarity, but causes decreased intraburst firing frequency, while in pre-I neurons, it induces hyperpolarization of $E_{m}$ and decreased intraburst firing frequency. These results indicate that in brainstem-spinal cord preparation of neonatal rat, the $\alpha 4 \beta 2$ nAChR subunit participates in the regulation of Insp neuronal activity, while both the $\alpha 4 \beta 2$ and $\alpha 7 \mathrm{nAChR}$ subunits are present in Pre-I neurons and cooperate to modulate $\mathrm{C} 4$ respiratory rate.

In the brainstem-spinal cord preparation used in this study, ACh produces increases in $\mathrm{C} 4$ respiratory rate that can be blocked partially by atropine, a muscarinic $\mathrm{ACh}$ receptor antagonist (Murakoshi et al., 1985).

In this same preparation, the application of DH- $\beta$-E has no effect on ACh-induced increases in $\mathrm{C} 4$ respiratory rate, but the additional application of atropine completely blocks ACh-induced response (Murakoshi et al., 1985). Moreover, Meca has no effect on ACh-induced increases in $\mathrm{C} 4$ respiratory rate and the sole application of gallamine, a NMBA, also shows no effect on $\mathrm{C} 4$ respiratory rate (Monteau et al., 1990). Taken together, these previous studies have suggested that nAChRs are not involved directly in central respiratory control of brainstem-spinal cord preparation from neonatal rats, in which muscarinic ACh receptors play the dominant role, and 
that the contribution of cholinergic mechanisms to respiratory rhythm generation at rest is slight. However, our previous work has demonstrated that the sole application of NMBAs, which function as muscular nAChR antagonists, induces dose-dependent reductions in $\mathrm{C} 4$ respiratory rate (Sakuraba et al., 2003) and respiratory $\mathrm{CO}_{2}$ responsiveness (Sakuraba et al., 2005). It also has been shown that respiratory $\mathrm{CO}_{2}$ responsiveness is partly inhibited by the sole application of Meca and DH- $\beta$-E in the isolated brainstem-spinal cord preparation of neonatal rat (Kuwana et al., 2000). These findings strongly suggest that central respiratory control, including chemosensitivity, is directly mediated by nAChRs in the isolated brainstem-spinal cord preparation of neonatal rats.

nAChRs are expressed in the RVLM, which has been identified as a locus of central respiratory control. These receptors are made up of two functional subunits, $\alpha 4 \beta 2$ and $\alpha 7$ (Wada et al., 1989; Dominguez del Toro et al., 1994). In a previous study, NMBAs were shown to inhibit neuronal $\alpha 4 \beta 2$ and $\alpha 7 \mathrm{nAChRs}$ expressed in Xenopus oocyte, which was interesting in that NMBAs are known to be antagonists of muscular nAChR (Chiodini et al., 2001). Given these and our previous results (Sakuraba et al., 2003, 2005), we hypothesized that both the $\alpha 4 \beta 2$ and $\alpha 7$ nAChRs are involved directly in central respiratory control. And, in fact, we found that the sole administration of Meca, DH- $\beta$ E, MLA, and $\alpha$-BgTx decrease C4 respiratory rate and that RJR increases $\mathrm{C} 4$ respiratory rate in the isolated brainstemspinal cord preparation of neonatal rats.

In previous studies using medullary slice preparations from neonatal rats, nicotineinduced increases of respiratory frequency are completely blocked by Meca (Shao and Feldman, 2001), hexamethonium (Shao and Feldman, 2002), and DH- $\beta$-E (Shao and Feldman, 2002), but are not blocked by MLA or $\alpha$-BgTx (Shao and Feldman, 2002). It also was reported that RJR increases respiratory frequency in a medullary slice preparation (Shao and Feldman, 2002).

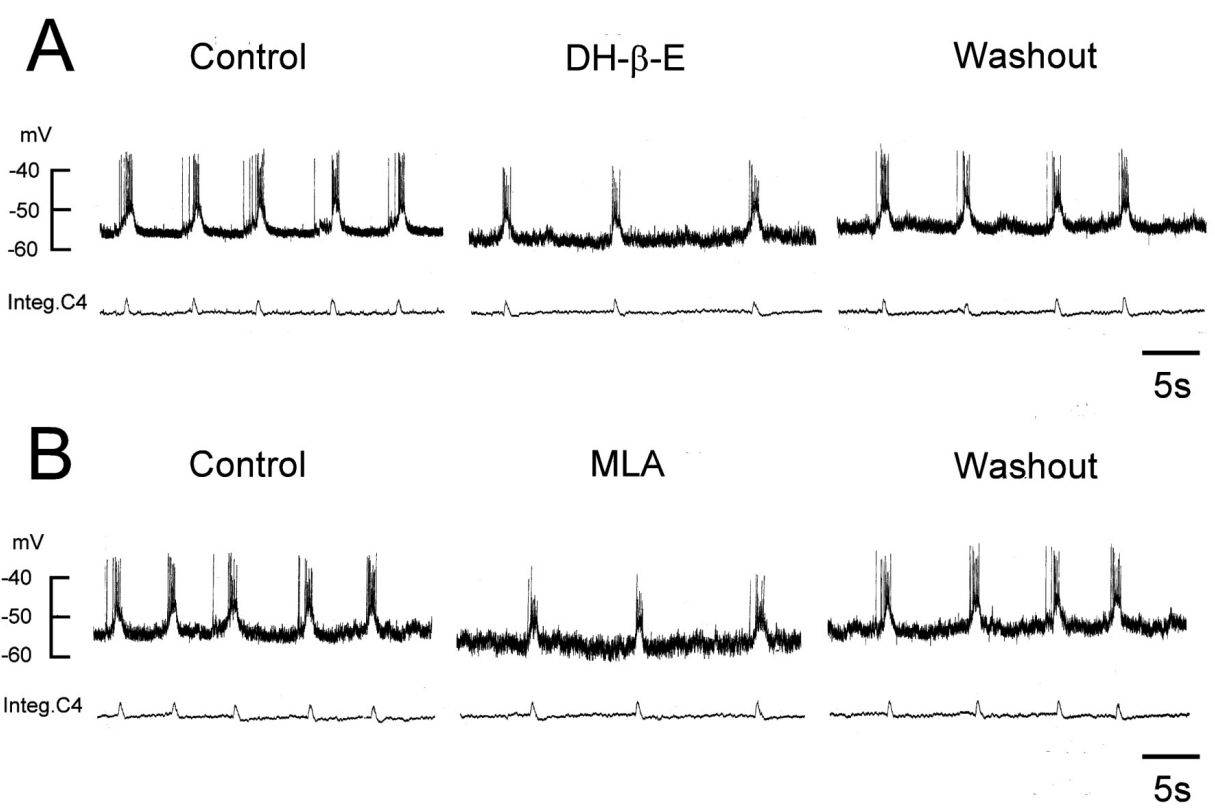

Figure 3: Effects of DH- $\beta$-E (A) and MLA (B) on the activity of preinspiratory neurons. Top traces show the membrane potential of preinspiratory neurons before (Control), during (DH- $\beta-\mathrm{E} 20 \mu \mathrm{M}$ or MLA $20 \mu \mathrm{M}$ ), and after the application of DH- $\beta$-E and MLA. Bottom traces show integrated C4 (Integ.C4) activity (Washout). 
TABLE 3

Effects of DH- $\beta$-E and MLA on preinspiratory neuron and $\mathrm{C} 4$ respiratory rate

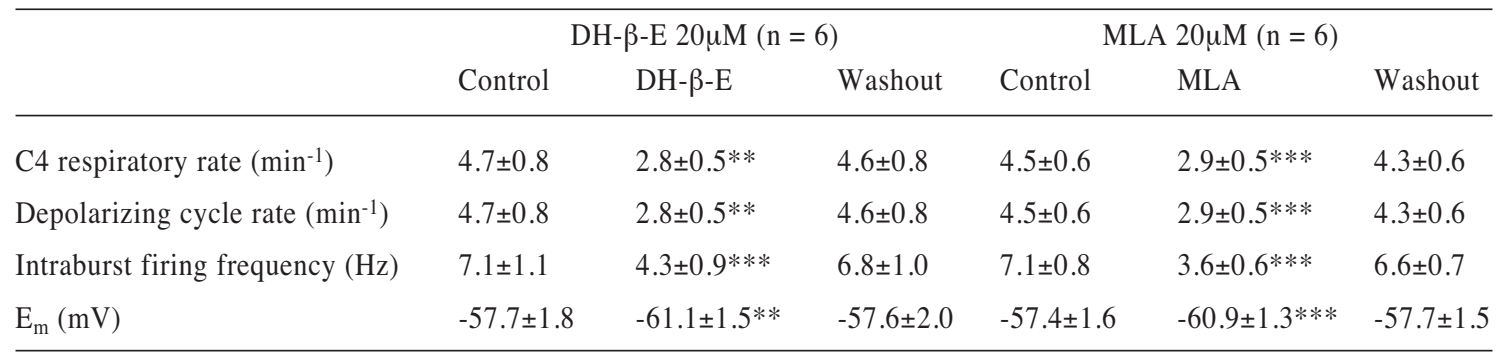

DH- $\beta$-E: dihydro- $\beta$-erythroidine; MLA: methyllycaconitine; $\mathrm{E}_{\mathrm{m}}$ : membrane potential

$* P<0.05$

$* * P<0.01$

$* * * P<0.001$

These past studies indicated that respiratory frequency is modulated by $\alpha 4 \beta 2$, but not by $\alpha 7 \mathrm{nAChR}$, at least in medullary slice preparations from neonatal rats. This, however, is not consistent with our results in which both $\alpha 4 \beta 2$ and $\alpha 7 \mathrm{nAChR}$ are shown to contribute to central respiratory control. Pre-I neurons are absent in medullary slice preparations, but present in isolated brainstem-spinal cord preparations of neonatal rats, a difference that prompted us to study the effects of DH- $\beta$-E and MLA on Pre-I neurons and Insp neurons.

Pre-I neurons play a crucial role in the generation of respiratory rhythm (Onimaru et al., 1988; Onimaru et al., 1989; Onimaru et al., 1997; Onimaru and Homma, 2003) and the determination of motoneuron burst timing (Mellen et al., 2003; Sakuraba et al., 2003) in brainstem-spinal cord preparations of neonatal rats. However, the role of nAChRs in respiratory neurons has been investigated only in medullary slice preparation of neonatal rats, in which the Pre-I neurons are absent. In these slice preparations, a low concentration of nicotine induces a tonic inward current and increases in the frequency and amplitude of spontaneous excitatory postsynaptic current in preBötzinger Complex Insp neurons (Shao and Feldman, 2002). These nicotineinduced effects on preBötzinger Complex Insp neurons can be reversed by DH- $\beta-\mathrm{E}$ and are unaffected by MLA or $\alpha$-BgTx (Shao and Feldman, 2002). The authors of that study concluded that $\alpha 4 \beta 2$ nAChRs modulate respiratory pattern via preBötzinger Complex Insp neurons. This is certainly consistent with our findings that DH- $\beta$-E has an inhibitory effect on Insp neurons, i.e. hyperpolarization of $\mathrm{E}_{\mathrm{m}}$, and causes reductions in intraburst firing frequency, drive potential duration, and drive potential amplitude. However, we also found that $\mathrm{DH}-\beta-\mathrm{E}$ induces hyperpolarization of $E_{m}$ and a reduction in intraburst firing frequency in Pre-I neurons. These findings strongly suggest that $\alpha 4 \beta 2$ nAChRs are located in both Insp and Pre-I neurons, where they serve to modulate central respiratory activities.

We have further shown that MLA also induces hyperpolarization of $E_{m}$ and reductions in intraburst firing frequency in Pre-I neurons. And although it decreases intraburst firing frequency in Insp neurons, MLA does not affect their $\mathrm{E}_{\mathrm{m}}$, drive potential duration or drive potential amplitude. It has been shown that Insp neurons receive excitatory synaptic connections from Pre-I neurons (Onimaru et al., 1992, 1996, 1997; Ballanyi et al., 1999; Takeda et al., 2001). Taking this mechanism into account, we speculate that MLA mainly exerts its inhibitory effect on Pre-I, but not Insp, neurons, thereby reducing the excitatory drive from Pre-I neurons to Insp neurons and lowering the intraburst firing frequency of Insp neurons as an indirect result. 
Furthermore, $\alpha 7 \mathrm{nAChRs}$ are expressed in presynaptic terminal and mediate $\mathrm{Ca}^{2+}$ entry via voltage-sensitive $\mathrm{Ca}^{2+}$ channels, and $\alpha 7 \mathrm{nAChRs}$ themselves are high permeable of $\mathrm{Ca}^{2+}$ for the release of $\mathrm{ACh}$ in the central nervous system (McGehee et al., 1995; Gray et al., 1996; Wonnacott, 1997). In the brainstem-spinal cord preparation, voltage-sensitive $\mathrm{Ca}^{2+}$ channels are related to the initiation and termination of hyperpolarization and depolarization of Pre-I neurons (Onimaru et al., 1996). Therefore, we can speculate that $\alpha 7 \mathrm{nAChRs}$ in Pre-I neurons partly characterize the Pre-I neuron burst and affect the respiratory rhythm.

In contrast to our previous study (Sakuraba et al., 2003), neither DH- $\beta$-E nor MLA induce a desynchronization of $\mathrm{C} 4$ respiratory rate and depolarizing cycle rate of Pre-I neurons during drug-induced respiratory depression. However, the NMBA used in the previous study was a muscular $\mathrm{nAChR}$ antagonist, not a pure neuronal nAChR antagonist, and we have not analyzed how these drugs might suppress central respiratory activity. It would be interesting to study this question by simultaneous bath application of DH- $\beta-\mathrm{E}$ and MLA in a future study. Further studies also are needed to analyze the different effects of NMBAs and neuronal nAChR antagonists on the desynchronization of $\mathrm{C} 4$ respiratory rate and depolarizing cycle rate in Pre-I neurons.

$\mathrm{Ca}^{2+}$ entry through neuronal nAChR modulates many biological processors in nervous tissue, and their permeability through $\alpha 4 \beta 2$ and $\alpha 7 \mathrm{nAChRs}$ are different (Fucile et al., 2005). Nevertheless, in our study, the responses of $\mathrm{C} 4$ and Pre-I neuron activities induced by the effects of MLA and DH- $\beta$-E are not different. Therefore, further studies are needed to analyze the relationship between neuronal nAChRinduced $\mathrm{Ca}^{2+}$ permeability change and respiratory activity.

In conclusion, both $\alpha 4 \beta 2$ and $\alpha 7 \mathrm{nAChR}$ subunits are involved in central respiratory control in brainstem-spinal cord preparations from neonatal rats, and $\alpha 4 \beta 2$ nAChRs function in both Pre-I and Insp neurons, while $\alpha 7 \mathrm{nAChRs}$ function solely in Pre-I neurons.

\section{ACKNOWLEDGEMENTS}

This work was supported in part by the Keio Gijuku Postgraduate School Fund for the Advancement of Research (S.S.), the Keio University Grant-in-Aid for Encouragement of Young Medical Scientists (S.S.), the Smoking Research Foundation (S.K.), and the Grant-in-Aid for Scientific Research from the Japanese Ministry of Education, Science and Culture (J.K. and J.T.).

\section{REFERENCES}

BALLANYI K, ONIMARU H, HOMMA I (1999) Respiratory network function in the isolated brainstemspinal cord of newborn rats. Prog Neurobiol 59: 583-634

BLAIR PS, FLEMING PJ, BENSLEY D, SMITH I, BACON C, TAYLOR E, BERRY J, GOLDING J, TRIPP J (1996) Smoking and the sudden infant death syndrome: Results from the 1993-5 case-control study for confidential inquiry into stillbirths and deaths in infancy. Brit Med J 313: 195-198

BURTON MD, NOURI M, KAZEMI H (1995) Acetylcholine and central respiratory control: Perturbations of acetylcholine synthesis in the isolated brainstem of the neonatal rat. Brain Res 670: 39-47

BURTON MD, JOHNSON D, KAZEMI H (1997) The central respiratory effects of acetylcholine vary with CSF pH. J Autonom Nerv Syst 62: 27-32

CHIODINI F, CHARPANTIER E, MULLER D, TASSONUI E, FUCHS-BUDER T, BERTRAND D (2001) Blockade and activation of the human neuronal nicotinic acetylcholine receptors by atracurium and laudanosine. Anesthesiology 94: 643-651

DOMINGUEZ DEL TORO E, JUIZ JM, PENG $X$, $\begin{array}{llll}\text { LINDSTROM } & \mathrm{J}, \quad \text { CRIADO M }\end{array}$ Immunocytochemical localization of the alpha 7 subunit of the nicotinic acetylcholine receptor in the rat central nervous system. J Comp Neurol 349: 325-342

EUGENIN J, NICHOLLS JG (1997) Chemosensory and cholinergic stimulation of fictive respiration in isolated CNS of neonatal opossum. J Physiol, London 501: 425437

EUGENIN J, LLONA I, INFANTE CD, AMPUERO E (2001) In vitro approach to the chemical drive of breathing. Biol Res 34: 117-122

FUCILE S, SUCAPANE A, EUSEBI F (2005) Ca2+ permeability of nicotinic acetylcholine receptors from rat dorsal root ganglion neurones. J Physiol 15(565,Pt 1): $219-28$

GRAY R, RAJAN AS, RADCLIFFE KA, YAKEHIRO M, DANI JA (1996) Hippocampal synaptic transmission enhanced by low concentrations of nicotine. Nature 383: 713-716

HUANG YH, BROWN AR, COSTY-BENNETT S, LUO A, FREGOSI RF (2004) Influence of prenatal nicotine exposure on postnatal development of breathing pattern. Resp Physiol Neurobiol 143: 1-8

KUWANA S, OKADA Y, NATSUI T (1998) Effects of extracellular calcium and magnesium on central respiratory control in the brainstem-spinal cord of neonatal rat. Brain Res 786: 194-204

KUWANA S, OKADA Y, IWANAMI M (2000) Effects of 
nicotinic ACh receptor antagonists on central respiratory chemosensitivity in the neonatal rat. Neurosci Res 24 (Suppl): S172

MCGEHEE DS, HEATH MJ, GELBER S, DEVAY P, ROLE LW (1995) Nicotine enhancement of fast excitatory synaptic transmission in CNS by presynaptic receptors. Science 269: 1692-1696

MELLEN NM, JANCZEWSKI WA, BOCCHIARO CM, FELDMAN JL (2003) Opioid-induced quantal slowing reveals dual networks for respiratory rhythm generation. Neuron 37: 821-826

MONTEAU R, MORIN D, HILAIRE G (1990) Acetylcholine and central chemosensitivity: In vitro study in the newborn rat. Respir Physiol 81: 241-254

MURAKOSHI T, SUZUE T, TAMAI S (1985) A pharmacological study on respiratory rhythm in the isolated brainstem-spinal cord preparation of the newborn rat. Bri J Pharmacol 86: 95-104

OKADA Y, CHEN Z, KUWANA S (2001) Cytoarchitecture of central chemoreceptors in the mammalian ventral medulla. Respir Physiol 129: 13-23

ONIMARU H, HOMMA I (1987) Respiratory rhythm generator neurons in medulla of brainstem-spinal cord preparation from newborn rat. Brain Res 403: 380-384

ONIMARU H, ARATA A, HOMMA I (1988) Primary respiratory rhythm generator in the medulla of brainstem-spinal cord preparation from newborn rat. Brain Res 445: 314-324

ONIMARU H, ARATA A, HOMMA I (1989) Firing properties of respiratory rhythm generating neurons in the absence of synaptic transmission in rat medulla in vitro. Exp Brain Res 76: 530-536

ONIMARU H, HOMMA I, IWATUKI K (1992) Excitation of inspiratory neurons by preinspiratory neurons in rat medulla in vitro. Brain Res Bull 29: 879-82

ONIMARU H, BALLANYI K, RICHTER DW (1996) Calcium-dependent responses in neurons of the isolated respiratory network of newborn rats. J Physiol 491: 677-695

ONIMARU H, ARATA A, HOMMA I (1997) Neuronal mechanisms of respiratory rhythm generation: an approach using in vitro preparation. Jpn J Physiol 47: 385-403

ONIMARU H, HOMMA I, (2003) A novel functional neuron group for respiratory rhythm generation in the ventral medulla. J Neurosci 23: 1478-1486

RICHERSON GB (1998) Cellular mechanisms of sensitivity to $\mathrm{pH}$ in the mammalian respiratory system. In: KAILA K, RANSOM BR (eds) $\mathrm{pH}$ and Brain Function. New York: Wiley-Liss. pp: 503-593
ROBINSON DM, PEEBLES KC, KWOK H, ADAMS BM, CLARKE LL, WOOLLARD GA, FUNK GD (2002) Prenatal nicotine exposure increases apnoea and reduces nicotinic potentiation of hypoglossal inspiratory output in mice. J Physiol 538: 957-973

SAKURABA S, KUWANA S, OCHIAI R, OKADA Y, KASHIWAGI M, HATORI E, TAKEDA J (2003) Effects of neuromuscular blocking agents on central respiratory control in the isolated brainstem-spinal cord of neonatal rat. Neurosci Res 47: 289-298

SAKURABA S, KUWANA S, ERIKSSON LI, OKADA Y, OCHIAI R, KASHIWAGI

M, HATORI E, LINDAHL SGE, TAKEDA J (2005) Effects of neuromuscular blocking agents on central respiratory chemosensitivity in newborn rats. Biol Res 38: $225-33$

SHAO XM, FELDMAN JL (2000) Acetylcholine modulates respiratory pattern: effects mediated by M3like receptors in preBötzinger complex inspiratory neurons. J Neurophysiol 83: 1243-1252

SHAO XM, FELDMAN JL (2001) Mechanisms underlying regulation of respiratory pattern by nicotine in preBötzinger complex. J Neurophysiol 85: 2461-2467

SHAO XM, FELDMAN JL (2002) Pharmacology of nicotinic receptors in preBötzinger complex that mediate modulation of respiratory pattern. J Neurophysiol 88: 1851-1858

SHAO XM, FELDMAN JL (2005) Cholinergic neurotransmission in the preBötzinger Complex modulates excitability of inspiratory neurons and regulates respiratory rhythm. Neuroscience 130: 10691081

SMITH JC, ELLENBERGER HH, BALLANYI K, RICHTER DW, FELDMAN JL (1991) Pre-Bötzinger complex: A brain stem region that may generate respiratory rhythm in mammal. Science 254: 716-719

TAKEDA S, ERIKSSON LI, YAMAMOTO Y, JOENSEN H, ONIMARU H, LINDAHL SG (2001) Opioid action on respiratory neuron activity of the isolated respiratory network in newborn rats. Anesthesiology 95: 740-749

WADA E, WADA K, BOULTER J, DENERIS E, HEINEMANN S, PATRICK J, SWANSON LW (1989) Distribution of alpha 2, alpha 3, alpha 4 , and beta 2 neuronal nicotinic receptor subunit mRNAs in the central nervous system: a hybridization histochemical study in the rat. J Comp Neurol 284: 14-335

WONNACOTT S (1997) Presynaptic nicotinic ACh receptors. Trends Neurosci 20: 92-98 